\title{
Yarn Wrapping Sticks - How My Own Arts Practice Informed My Work with Clients and Students
}

\author{
Jacinta McAvoy \\ The MIECAT Institute, Australia
}

Keywords: anxiety, calming, meaning making, daily ritual

My work with clients and students creating yarn wrapped sticks began with my own arts practice.

As I walked through the local Fitzroy Gardens toward my first day of work at MIECAT, I pondered establishing a daily ritual to begin each day - to land me in the space and to calm my mind before starting work.

I had tried to establish daily art rituals previously with little success, so I knew that for it to become a part of my every day routine it had to be a simple process using simple materials and preferably connected with nature. As I walked, I found myself being drawn to small sticks at the base of the many trees in the park and started to collect the ones that caught my attention - landing at work with a small bundle of twigs and the seed of a thought.

I found a small box of wools and fleece in the store room, selected some colors and textures that pleased me, and began to wrap some sticks. It was simple and quick and I made sure I worked with focused attention. I found the exercise surprisingly satisfying. The act of noticing (selecting the sticks as I walked), the feel of the sticks in my hand, the selection of colors and textures from the stash of wool and the act of wrapping the sticks was grounding and calming.

As the daily practice continued, it became a ritual of feeling into my body and asking myself about the day ahead. Sometimes the sticks were wrapped with a single yarn though, more often than not, a combination of colors, textures and wrapping techniques were used. On occasion, the sticks became an indication of how my day would eventually unfold. A friend started calling them my oracle sticks!

Others were intrigued and tried them too - two colleagues created sticks as they walked to work together, wrapping them in found materials they collected along the way. They, too, connected with the simplicity of the process and found themselves more aware of their surroundings.

Later, I offered the practice to a group of women I worked with at a local shelter. I introduced it as a warm-up exercise - describing the stick-wrapping as a process I had started as a way of landing in a space to reduce my own anxiety in a new situation. I was delighted when they settled into their making and created yarn wrapped sticks of their own. They also found the experience of wrapping both calming and grounding and - as they discussed the process and talked about their individual work - the participants found their sticks held meaning and gave them an access point from which they were 


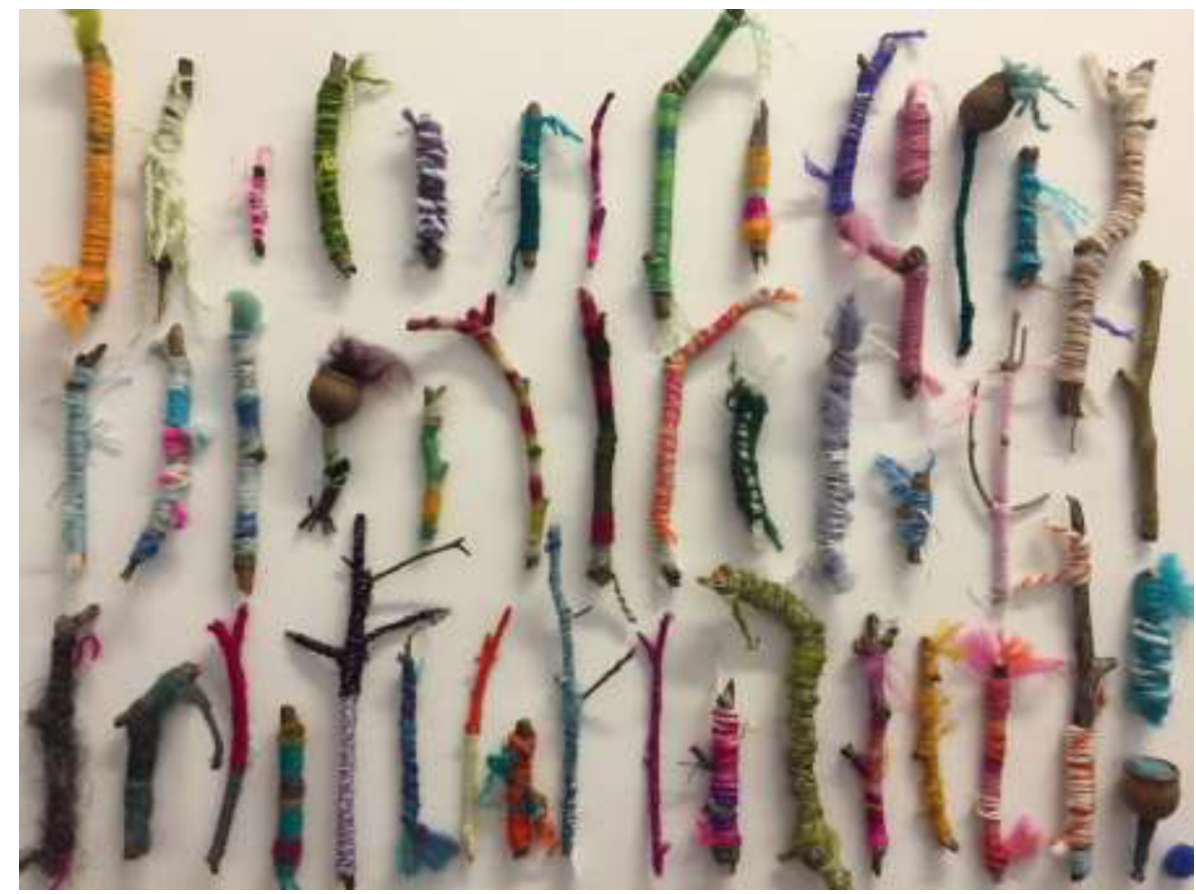

FIGURE 1 | Jacinta, 2018, Collection of yarn wrapped sticks.

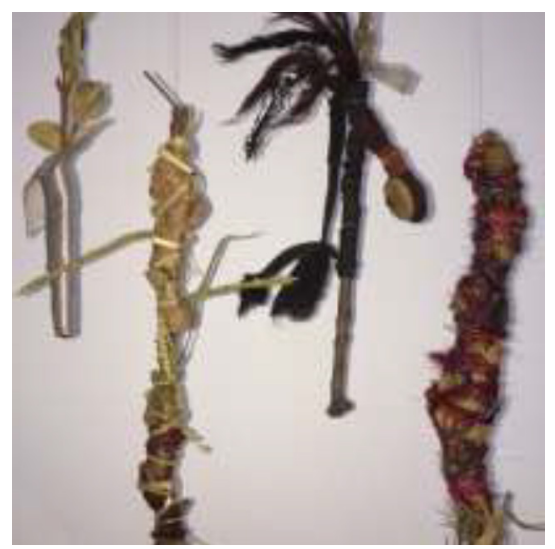

FIGURE 2 | 2018, Sticks wrapped in found materials

able to tell their stories. Who would have thought a simple stick would initiate such discussion and reflection!

When I recently met with a small group of students for the first time, I introduced the process to them; this time I asked the group to create their sticks while they reflected on their hopes and concerns around a subject they were about to begin. The focus was slightly different - but once again I found the yarn wrapped sticks held meaning and 
supported the students in identifying their feelings and landing in the space of something unknown.

I continue to use the stick wrapping as a way of landing in a space and calming feelings of anxiety - though it is no longer a daily practice. Whilst establishing and maintaining a daily arts practice remains elusive, the stick wrapping is a process I will continue to adapt and use - both for myself and in my work with others.

\section{About the Author}

Jacinta McAvoy (MTAP, AThR).The MIECAT Institute.E-Mail: jacinta@miecat.edu.au 